Gazi Mühendislik Bilimleri Dergisi

2019, 5(2): 138-150

Araștırma Makalesi/Research Article

gmbd.gazipublishing.com

\title{
LED Işık Kaynaklı, Enerji Tasarruflu ve Yüksek Verimli Ofis Aydınlatma Armatürü Tasarımı
}

\author{
Emre YILMAZ ${ }^{* a}$, İsmail ŞAHİN ${ }^{\mathrm{a}}$, Nuri Yunus KOCADAĞ ${ }^{\mathrm{b}}$ \\ a,* Gazi Üniversitesi Fen Bilimleri Enstitüsü Endüstriyel Tasartm Mühendisliği Bölümü, ANKARA 06500, TÜRKIYYE \\ $b^{b, *}$ Kırlkkale Üniversitesi Fen Bilimleri Enstitüsü Elektrik Elektronik Mühendisliği Bölümü, KIRIKKALE 71450, TÜRKIYE
}

MAKALE

BILLİSI

Alınma: 27.03.2019

Kabul: 18.07.2019

\section{Anahtar Kelimeler:}

Aydinlatma,

Aydınlatma Armatürü,

Ofis Aydınlatma,

LED Aydinlatma,

LED Panel

*Emre YILMAZ:

e-posta:

emre.yilmaz@aydinlat

ma.org

\section{ÖZET}

Son yıllarda, tüm dünyada enerji verimliliğinin artan önemi sonucunda, aydınlatmada verim konusunda da bilinç ve çalışmalar artmış, LED aydınlatmaya geçiş başlamıştır. Dünyadaki gidişat diğer teknolojilerde olduğu gibi aydınlatma armatürlerinde de daha verimli, daha uzun ömürlü, bakım gerektirmeyen, zararlı maddeler içermeyen, gelişen ve değişen teknolojiye uyumlu ve yönetilebilen LED aydınlatma sistemlerine doğru gitmektedir. Ülkemizde yeni projeler haricinde LED ışık kaynaklı armatürlerin yaygın olmaması, halen LED'li armatürlerin birim fiyatlarının yüksek olması, mevcut aydınlatma pazarının, bugünkü durumda bile, büyük çoğunluğunun bilinen geleneksel 1şık kaynaklarıyla yapılmış olması, LED aydınlatma konusunda ciddi firsatlar olduğunu göstermektedir.

Bu çalışmada, hali hazırda genel aydınlatma armatürü olarak kullanılan 4x18 ve 4x14 floresan 1şık kaynaklı armatürler yerine geçebilecek ve bu armatürlere göre \%40-\%60 enerji tasarrufu sağlayacak LED ışık kaynaklı ofis aydınlatma armatürü tasarlanmıştır. Ofis aydınlatma armatürü, dekoratif görünümden öte işlevsellik, yüksek performans ve düşük maliyet esasları göz önünde bulundurularak tasarlanmıştır.

\section{Design of Energy Saving and High Efficiency Office Lighting Fixture with LED Light Source}

\section{ARTICLE \\ INFO \\ Received: 27.03.2019 Accepted: 18.07.2019 \\ Keywords: \\ Lighting, \\ Light Fixture, \\ Office Lighting, \\ LED Lighting, \\ LED Panel \\ Emre YILMAZ \\ e-mail: \\ emre.yilmaz@aydinlat ma.org}

\begin{abstract}
In recent years, as a result of the increasing importance of energy efficiency all over the world, awareness and works have also been increased in lighting, and transition to LED lighting has begun. As in other technologies, the trend in the world goes towards LED lighting systems that are more efficient, longer lasting, maintenance free, free of harmful substances, compatible with the developing and changing technology. The fact that LED luminaires are not widespread except for new projects in our country, the unit prices of LED luminaires are still high, the current lighting market, even in the current situation, the vast majority of them are made with the traditional light sources shows that there are serious opportunities for LED lighting.

In this study, LED light welded office lighting fixture will be designed to replace 4x18 and 4x14 fluorescent light source luminaires which are currently used as general lighting fixtures and provide $40 \%-60 \%$ energy saving compared to these luminaires. The office lighting fixture will be designed considering the functionality, high performance and low cost principles rather than the decorative appearance.
\end{abstract}

https://dx.doi.org/10.30855/gmbd.2019.02.03 


\section{GIRISŞ (INTRODUCTION)}

Günümüzde LED teknolojisi neredeyse her alanda kendine yer edinmektedir. LED teknolojisinin kullanıldığı alanlardan bir tanesi de genel aydınlatma uygulamalarıdır. Dünya genelinde hem iç mekân hem de dış mekân aydınlatmalarının, LED teknolojisiyle yenilendiği bir dönüşüm dönemi yaşanmaktadır. LED aydınlatma, enerji tasarrufu, uzun ömür, aydınlatma verimliliği ve düşük bakım maliyetleri özelliklerinden dolayı en bilinir aydınlatma çeşidi olmuştur. Ev, ticari veya ofis binaları, fabrika, dış mekân ve otomotiv gibi pek çok alanda kullanılmaktadır. LED aydınlatmanın performansı, güç faktörü, verimlilik, toplam harmonik distorsiyon (THD) ölçümleriyle belirlenir [1-4].

LED’ler yüksek ışı verimine sahip aydınlatma elemanları olsa da, bir sistem içine dâhil edildiğinde 1şık çıktısında bazı düşüşler görülmektedir. Işık kaybını kontrol altında tutmak için ürün tasarımı ve malzeme seçimi son derece önemlidir. Doğru tasarlanmış bir aydınlatma elemanı, düşük güç tüketimiyle yüksek 1 şık çıktısına sahip olacak, bu sayede enerji tasarrufu sağlayacaktır.

Aydınlatma armatürü, başlangıç 1 şı akısının yüzde 30'unu kaybettiğinde, kullanım ömrü tamamlanmış olarak kabul edilir [5]. Uzun kullanım ömrüne ulaşabilmek için aydınlatma armatürü iyi bir termal yönetime sahip olmalıdır.

Ofis aydınlatması ve LED teknolojisi üzerine yapılan çalışmalardan bazıları şu şekilde özetlenebilir; Malezya'nın ulusal uygulamalı Ar-Ge merkezi MIMOS Berhad'dan bir grup araştırmacının yaptığı çalışmada renk sıcaklığının insan üzerindeki psikolojik ve fizyolojik etkileri üzerine 10 ofis çalışanı üzerinde kontrollü bir deney yapmıştır. $\mathrm{Bu}$ çalışmayla; bilgisayar tabanlı işler yapılan ofis ortamlarında soğuk beyaz ve gün 1 şı̆̆ 1 renk sicaklıklarının sıcak beyaz renk sıcaklığına göre daha faydalı olduğu sonucuna varılmıştır [6].

Yonsei Üniversitesi, Mimarlık Mühendisliği Bölümü'nden Byung-Lip Ahn'ın önderlik ettiği çalışmada LED aydınlatmaların ofislerde soğutma ve 1sıtma sistemlerine dolayısıyla enerji tüketimine olan genel etkisi araştırılmıştır. Bu çalışma sonucunda da ofis aydınlatmalarında LED ışı kaynaklı aydınlatma armatürlerinin kullanımının binanın enerji verimliliğini artıracağı sonucuna varılmıştır [7].
Görsel konfor olasılı̆̆1 (Visual Comfort ProbabilityVCP), IESNA (Kuzey Amerika Aydinlatma Mühendisleri Derneği) tarafından geliştirilmiştir. İç mekân aydınlatmalarında gözlemcilerin belirlenen koşullar altında bir aydınlatma sistemine bakarken ki parlamanın rahatsız etme derecesi olasılığıdır [8]. VCP değeri 0-100 aralığında değişen, gözlemcilerden kimsenin aydınlatma konforundan memnun olmadığında 0 iken tüm gözlemcilerin memnun olması durumunda ise 100 olmaktadır.

İtalya'da INRIM araştırma enstitüsünde yapılan çalışmada genel olarak LED aydınlatmaların rahatsız edici kamaşmaya yol açtığı ancak bu sorunun 1 şık kaynağının bir difüzör yardımıyla gizlenerek aşılabildiği gösterilmiştir. Difüzör aynı zamanda daha homojen bir 1şık dağılımı sağlanmasına yardımcı olmaktadır [9].

Tayvan'da Nan Kai Teknoloji Üniversitesi'nde LED'lerin soğutma performansı üzerine yapılan çalışmada yüksek güçlü LED'lerin harcadığ 1 enerjinin \%20-30'unu 1şığa, kalan enerjiyi ise ısıya dönüştürdüğü ve açığa çıkan bu isının LED'lerin jonksiyon sıcaklığını artırarak LED'in 1 şık yoğunluğunu, renk dengesini ve ömrünü olumsuz etkilediğini belirtmiştir. Önerilen pasif soğutma sisteminin 1sıyı verimli bir şekilde dağıtarak, 1 şık kaynağının ömrünü uzatarak koruyabildiği sonucuna varılmıştır [10].

Tayvan'da Ulusal Kaohsiung Uygulamalı Bilimler Üniversitesi'nde Jin-Cherng Shyu önderliğinde yapılan çalışmada LED'lerde giriş gücünün büyük bir kısmının 1sıya dönüştüğü, açığa çıkının bu 1sının ciddi problemlere sebep olduğu belirtilmiştir. LED'in jonksiyon sicaklığının düşük seviyelerde tutulmasının yüksek 1 şık verimi, sabit 1 şı çıtısı, sabit dalga boyu ve daha uzun kullanım ömrü için bir anahtar olduğu belirtilmiştir [11].

İstanbul Teknik Üniversitesi, Enerji Enstitüsü, Enerji Planlaması ve Yönetimi Anabilim Dalı'ndan bir grup araştırmacı ofis aydınlatmalarında kullanılan $4 \times 18$ W'lı floresan lambalı armatürler yerine LED panel armatürlerin uygulanması halinde aydınlık düzeyleri ve düzgünlük gibi parametrelerdeki değişimleri ve olası enerji tasarrufu oranlarını belirlemeye çalışmıştır. $\mathrm{Bu}$ çalışma sonucunda, floresan lambalı armatürler yerine LED ışık kaynaklı panel armatürlerin birebir değişimiyle aydınlık düzeyinde $\% 1,3$ oranında artış, düzgünlük değerlerinde iyileşmeler ve enerji verimliliği 
açısından \%59 oranında ciddi bir tasarruf elde edildiği belirtilmiştir [12].

$\mathrm{Bu}$ çalışmada mevcut durumda ofis ortamlarının aydınlatılmasında kullanılan floresan 1 şı k kaynaklı geleneksel armatürlerin yerine geçecek, LED 1 şı kaynakl1, yüksek verimli ve enerji tasarruflu ofis aydınlatma armatürü tasarımı gerçekleştirilecektir. Geliştirilecek bu armatür ile ofis aydınlatmasında $\% 40-\% 60$ oranında enerji tasarrufu sağlanması ve uzun kullanım ömrüyle işletme ve bakım masrafları düşürülmesi amaçlanmaktadır.

Piyasada ofis aydınlatması için çeşitli firmalara ait LED 1şık kaynaklı panel armatürler bulunsa da, bu armatürlerin bir çoğu 1 ya da 2 yıl içerisinde arıza yapmaktadır. Burada bahsedilen arıza, 1şı̆̆ın tamamen kesilmesi olarak ortaya çıkmasa da zamana bağlı 1şı çıktısında düşüş olarak da görülebilmektedir. LED'lerin ve LED 1şık kaynaklı ürünlerin ömrünü etkileyen en önemli faktör sıcaklıktır. LED'ler üzerinde oluşan isı kontrol altına alınırsa, ışık kaynağı uzun yıllar sorunsuz bir şekilde çalışabilir. Bu çalışmada tasarlanacak LED modül kartının ömür öngörüsü, yapılacak termal analiz ve deney yardımıyla ortaya çıkartılacaktır.

\section{AYDINLATMA ARMATÜRÜ TASARIMI (LIGHTING FIXTURE DESIGN)}

\subsection{LED'li Işık Kaynağı (LED Light Source)}

Aydınlatma maksatlı bir ürün tasarımı yapılması istendiğinden öncelikle bu sisteme ait 1şık kaynağ 1 tasarlanmalıdır. LED'li 1 şı kaynağı tasarımında kullanılmak maksadıyla yüksek $1 s ̧ 1 k$ verimi sunan, mid-power LED ailesinin bir üyesi olan LM561B kodlu $1 / 2$ W'lık yüzey monte LED'leri tercih edilmiștir. Bu LED uygun koşullarda 160 lm/W'a kadar etkinlik faktörüne sahiptir.

Sürüş akımı artırıldığında, ışık akısı da artmakta ancak $\mathrm{lm} / \mathrm{W}$ ile gösterilen etkinlik faktörü değeri yani 1ş1k verimi düşmektedir. Yüksek verimli bir 1 ş1k kaynağı tasarlanması istendiğinden, üretici tarafindan belirtilen tipik sürüş akımı $65 \mathrm{~mA}$ veya bu değerin altında bir akım değeri tercih edilmelidir.

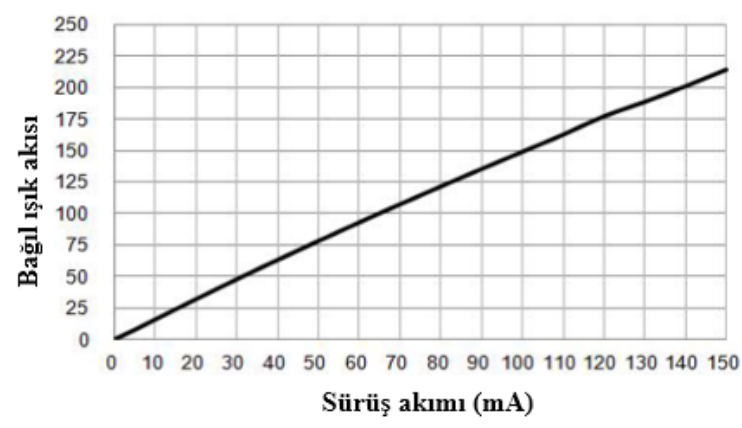

Şekil 1. Bağıl 1şık akısı ve sürüş akımı grafiği (Relative luminous flux and forward current graph) [13]

LM561B kodlu LED, genel aydınlatma maksatlı kullanılan diğer tüm LED'ler gibi 2700K'den $6500 \mathrm{~K}$ 'e kadar geniş renk sıcaklığı aralığında temin edilebilmektedir. Renksel geriverim indeksi (Ra) 80 'in üzerindedir. Bu da görsel konforun artmasını, tüm nesnelerin özgün renklerinde görülmesini sağlamaktadır.

LM561B kodlu mid-power LED'in zamana bağl1 1şık akısı ölçümleri (LM-80) üretici tarafından 100 ve $150 \mathrm{~mA}$ sürüş akımlarında 6.000 saat süre ile yapılmış, 36.000 saatten fazla ekonomik ömür garantisine sahip olduğu belirtilmiştir. Şekil 1'de LM561B LED'e ait bağıl 1şık akısı ve sürüş akım grafiği verilmiştir. LM-80 raporuna göre, $100 \mathrm{~mA}$ sürüş akımında LED'in lehim noktası sıcaklığı 55 ${ }^{\circ} \mathrm{C}, 85{ }^{\circ} \mathrm{C}$ ve $105{ }^{\circ} \mathrm{C}$ iken LED'in toplam 1 ş1k akısının başlangıç 1 şık akısına göre \%70 seviyesine düştüğü sürenin 36.000 saatten fazla olduğu görülmektedir. $\mathrm{Bu}$ süre LED'in ekonomik kullanım ömrünü göstermektedir.

Tablo 1. LM-80 test raporu'na göre TM-21 ömür öngörüsü (TM-21 Lifetime estimate according to LM-80 test

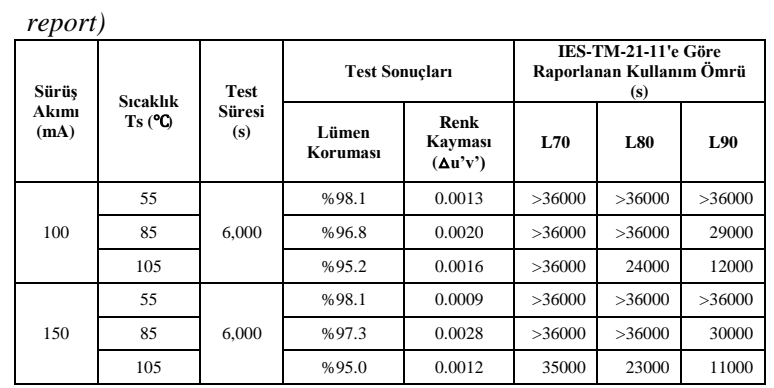

Tablo 1'de görüldüğü üzere, çalışma sicaklığ LED 1şık kaynaklarının ışık akılarını, ömürlerini ve renk özelliklerini etkilemektedir. Bu noktada LED 1şık kaynağı tasarımının bir sonraki aşaması olan elektronik devre kartı tasarımı öne çıkmaktadır. 
Çalışma kapsamında oluşturulan devre kartı için termal iletkenliği yüksek, düşük maliyetli FR4 malzeme seçilmiş, tasarımda LED'lerin termal yüzeyine uygun bakır soğutma alanları oluşturulmuştur.

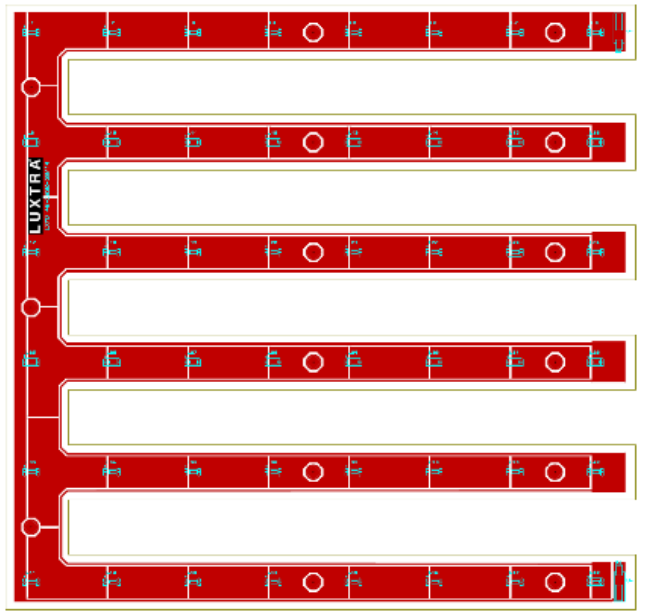

Şekil 2. LED modül baskı devre kartı (LED module printed circuit board)

PCB ve dizgi maliyetlerini azaltmak için dizgi sonrası birbirinin içinden el ile kolayca kırılarak çıkartılan Şekil 2'deki tarak tipi kart tasarımı yapılmıştır. Bir armatür içerisinde 4 tarak PCB yani 2 panel PCB kullanılacaktır.

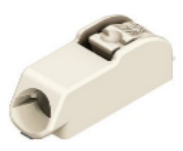

Şekil 3. Bir kutuplu SMD bağlantı klemensi (One pole SMD connection terminal block)

Sürücü-LED Modül ve LED Modül-LED Modül arasındaki bağlantının kolayca sök-tak yapılabilmesi için Şekil 3'teki SMD klemensin kullanılmasına karar verilmiş; WAGO'nun 2060-401 modeli 1 kutuplu, $4 \mathrm{~mm}$ bacak aralığına sahip SMD klemensin teknik çiziminde belirtilen footprint ölçülerine göre PCB üzerinde lehimleme yüzeyleri oluşturulmuştur.

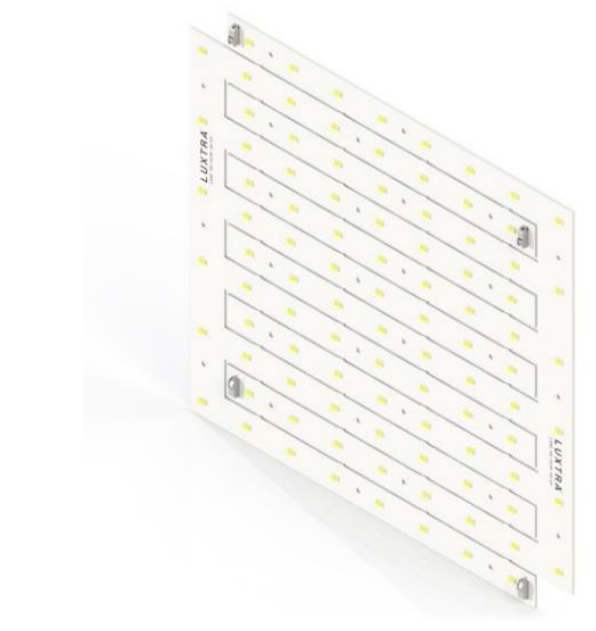

Şekil 4. LED modül 3 boyutlu panel modellemesi (LED module 3D panel modelling)

LED 1şık kaynağı tasarımının tamamlanmasından sonra, bu modüllerin içerisine monte edileceği, ofis ortamlarında kullanılabilecek uygun ölçülerde armatür gövdesi tasarımı yapılmalıdır.

\subsection{Aydınlatma Armatürü Gövde Tasarımı (Lighting Fixture Body Design)}

LED 1şık kaynağı için geliştirilen armatür gövdesi geleneksel aydınlatma armatürlerinden farklı değildir. Burada iki farklılık bulunmaktadır. Birincisi gövde üzerindeki montaj delikleridir. Bu delikler ışı kaynağını armatür gövdesine tutturmak için kullanılır. Delik konumları LED modül kartı üzerindeki montaj delikleri ile eşleştirilmelidir. Diğer bir farklılık da armatür gövdesinin iç derinliğidir. $4 \times 18$ T8 armatürlerde armatür derinliği $7-9 \mathrm{~cm}$ olurken, $4 \times 14$ T5 armatürlerde derinlik $4.5 \mathrm{~cm}$ ila $5,5 \mathrm{~cm}$ arasında değişmektedir. LED ışık kaynaklı armatürlerde de derinlik tasarımdan tasarıma değişmektedir. Referans tasarımda $7 \mathrm{~cm}$ kasa derinliği tercih edilerek 2 boyutlu açınım ve 3 boyutlu kasa çizimleri oluşturulmuştur. 


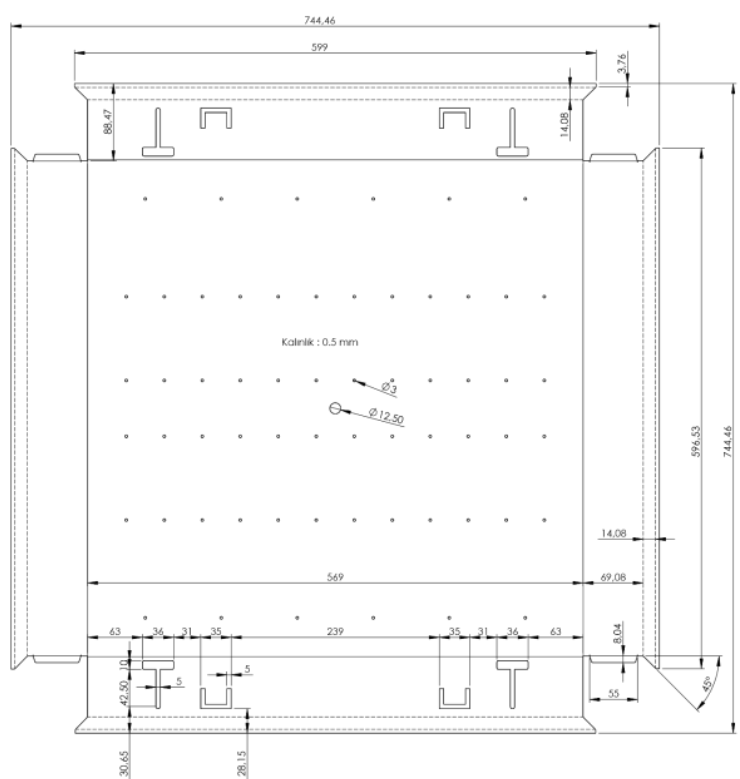

Şekil 5. Aydınlatma armatürü gövdesinin açınım resmi (Picture of the opening of the lighting fixture body)

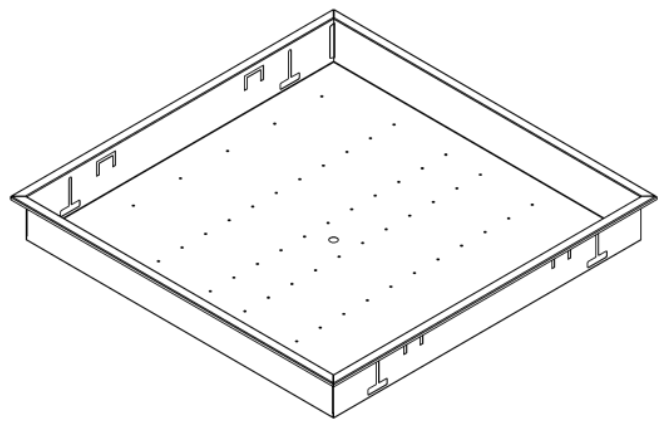

Şekil 6. Aydınlatma armatürü gövdesinin form verilmiş hali (Finished shape of lighting fixture body)

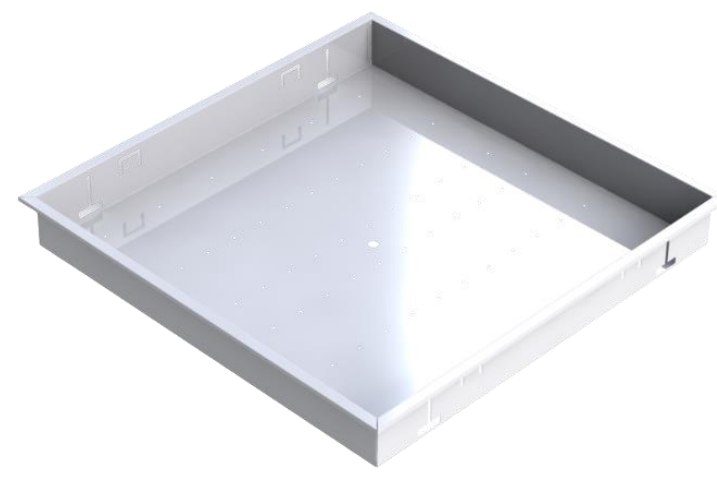

Şekil 7. Aydınlatma armatürü gövdesinin form verilmiş halinin 3 boyutlu gösterimi ( $3 D$ display of finished shape of lighting fixture body)
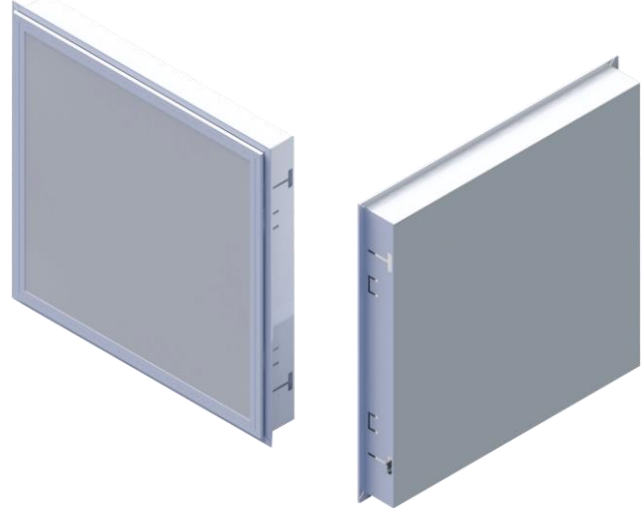

Şekil 8. Aydınlatma armatürü gövdesinin 3 boyutlu gösterimi ( $3 D$ display of lighting fixture body)

\subsection{Optik ve Işık Açısı (Optical and Light Angle)}

Açı kontrolü, 1şık kaynağını gizleme, 1şı̆̆ın homojen bir şekilde dağılması ve estetik bir görünüm sağlamak maksadıyla armatür tasarımında difüzör kullanılması gereklidir. Yongtek firmasının ürünlerinden PA-00S, PA-75S2, PA-90S ve PA92ER gibi birçok model difüzör teknik verileri incelenerek numune temin edilmiştir. Üretici verilerine göre bu difüzörler 1şı̆̆ $\% 74-\% 95$ verimlilikle armatür dışına iletebilmektedir. Polistiren (PS) malzemeden üretilmiş bu difüzörler, $99{ }^{\circ} \mathrm{C}$ 'ye kadar termal dayanım göstermektedir.

Polistiren, katı ve saydam bir plastik ham maddedir. Polistiren, dünyada plastik üretiminde en çok kullanılan hammadeler arasında yer almaktadır [17].

Şeffaflığı, iyi işlenebilmesi, akışkanlığı ve diğer birçok özellikleri nedeniyle pek çok uygulamada tercih edilmektedir.

Tablo 2. Yongtek PS mat S/S2 difüzör teknik detaylar1 (Yongtek PS matte S/S2 diffuser technical details)

\begin{tabular}{|c|c|c|c|c|c|}
\hline Model & Malzeme & $\begin{array}{c}\text { Plaka } \\
\text { Kalınlı } \\
\text { ğ }\end{array}$ & $\begin{array}{c}\text { Geçirgenliği } \\
\text { HZ\% }\end{array}$ & $\begin{array}{c}\text { Işık } \\
\text { Geçirgenliğ } \\
\text { i T/T\% }\end{array}$ & $\begin{array}{c}\text { Yüzey } \\
\text { Deseni }\end{array}$ \\
\hline $\begin{array}{c}\text { PA- } \\
90 \mathrm{~S}\end{array}$ & PS & $\begin{array}{c}1.5 \\
\mathrm{~mm}\end{array}$ & 88 & 90 & $\begin{array}{c}\text { Tek } \\
\text { tarafl } \\
\text { mat }\end{array}$ \\
\hline $\begin{array}{c}\text { PA- } \\
85 \mathrm{~S}\end{array}$ & PS & $\begin{array}{c}1.5 / 1.8 \\
\mathrm{~mm}\end{array}$ & 91 & 84 & $\begin{array}{c}\text { Tek } \\
\text { tarafl } \\
\text { mat }\end{array}$ \\
\hline PA- & PS & $\begin{array}{c}1.5 \\
\mathrm{~mm}\end{array}$ & 91 & 74 & $\begin{array}{c}\text { Çift } \\
\text { tarafl } \\
\text { mat }\end{array}$ \\
\hline $75 \mathrm{~S} 2$ & PS & $\begin{array}{c}1.5 \\
\mathrm{~mm}\end{array}$ & 92 & 63 & $\begin{array}{c}\text { Çift } \\
\text { tarafl } \\
\text { mat }\end{array}$ \\
\hline $\begin{array}{c}\text { PA- } \\
\text { 65S2 }\end{array}$ & PS & & & &
\end{tabular}


PA-75S2 modeli polistiren difüzör $1,5 \mathrm{~mm}$ kalınlıkta, 1şı̆̆ 1 minimum $\% 74$ oranında iletebilmektedir. Işık kaynağını gizlemede yüksek performans göstermektedir. $1,06 \mathrm{~g} / \mathrm{cm}^{\wedge} 3$ yoğunluğa sahip bu difüzör oldukça hafif ve istenilen ölçülerde kolayca kesilebilmektedir. UV ışınlarına dayanıklı, yüksek termal kararlılığı ile sararma ve solmaya gibi olumsuz özellikler göstermemektedir.

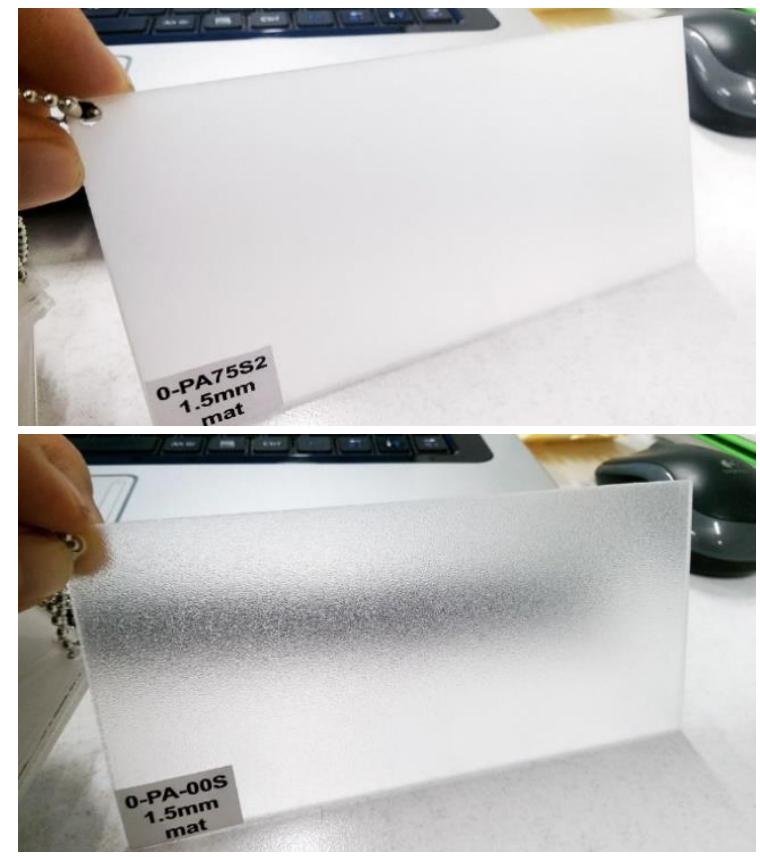

Şekil 9. PA75S2 ve PA-00S modelleri difüzör plakalar1 (PA75S2 and PA-00S models diffuser plates)

Kamaşma sorununun çözümüne yönelik; ışı̆̆ın optik algıda yarattığ olumsuzlukları yok etmek maksadıyla kasa derinliği $7 \mathrm{~cm}$ seviyesinde tutulmuştur. $\mathrm{Bu}$ derinlik PA-75S2 modeliyle 1 şık kaynağının gizlenmesinde de doğru bir tercihtir. 5 $\mathrm{cm}$ ve daha az derinliklerde LED'ler difüzör arkasında tane tane belirginleşmeye başlamaktadır. Şekil 10'da farklı kasa derinliklerinde 1 şık kaynağının görünürlüğü karşılaştırılmıştır.

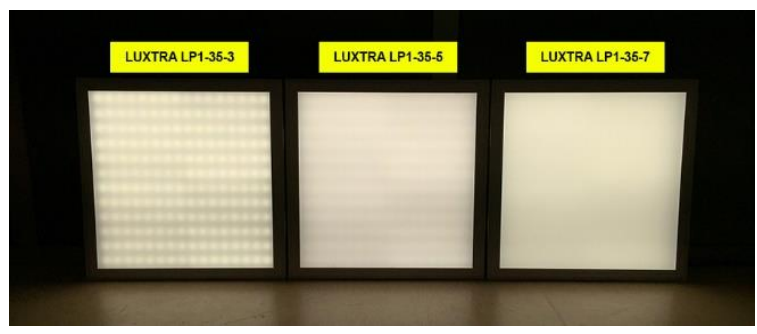

Şekil 10. Kasa derinliğinin 1şık kaynağının görünürlüğü üzerindeki etkisi (Effect of case depth on light source visibility)

\subsection{LED Sürücü Tasarımı (LED Driver Design)}

LED sürücü, istenilen verimlilik, THD, güç faktörü, güç değeri, maliyet ölçütlerine göre farklı devre tasarımlarına sahiptir. Temel olarak sabit gerilim ve sabit akım çeşidine sahip olan LED sürücüler $\mathrm{AC}-\mathrm{DC}$ sürüş topolojisine göre de farklılaşmaktadır. Buck, boost, buck-boost, flyback, yarım köprü, tam köprü, sepic, cuk, zeta olmak üzere çeşitlendirilmişlerdir.

Maliyet-performans olarak en güce bağl1 değişmekle birlikte en çok tercih edilen topolojiler flyback ve yarım köprü'dür. Flyback ile yüksek güç faktörü ve çıkış akımında regülasyon sağlanabilmektedir. Yüksek frekanslı anahtarlamada oluşan kayıplardan dolayı verimlilikleri \%87'den az olmaktadır. Yüksek güçlü uygulamalarda anahtarlama yapılan trafo üzerindeki kaçak endüktans ve kapasitans değerlerinin düşürülmesi gerekir [14-15].

Buck, boost, buck-boost, yarım ve tam köprü topolojilerinde devre giriş kısmında güç faktörü düzenlemesi yapılırken çıkış tarafından alınan geri besleme gerilim değerleri karşılaştırıcılar üzerinden değerlendirilerek anahtarlama frekanslarında değişiklikler yapılır. Böylece verimli, yüksek güç faktörü ve daha az bozunuma sahip DC çıkış ile LED yükü sürülmektedir.

$\mathrm{Bu}$ çalı̧̧mada, yapılacak olan LED sürücü yarım köprü topolojisine sahip olacaktır. $\mathrm{Bu}$ topoloji gereğince iki adet güç mosfeti ile yüksek frekansta yumuşak anahtarlama amaciyla seri paralel rezonans devresi olan LLC kullanılmaktadır. Şekil 13'te kullanılacak topolojinin devre üzerinde konumlandırılmasına yer verilmiştir. 
Yarım köprü sürücü devrelerinde sıfır akım algılayıcı (ZCD) ile anahtarlama yapıldığında akım sıfira düştüğünde anahtarlama yapılan entegre kapatılır, gerilim algılayıcı (ZVD) ile gerilim sıfira düştügünde tekrar açılır. Böylece yumuşak anahtarlama ile elektromanyetik enerji depolanır ve anahtarlama frekansı yükseltilerek verimlilik arttırılır [16].

Devre tasarımının giriş katında alternatif akımın inverter devresine distorsiyonsuz olarak alınabilmesi için paralel RC devresi kullanılmıştır. Devrenin AC girişinde elektromanyetik gürültüleri önleyen EMI filtresi bulunur. EMI filtresi şebekeden gelebilecek farklı frekanslardaki bozulmuş gerilimi süzmek için de oldukça faydalıdır. Bu tasarım için kullanılacak EMI filtresi endüktansı $2.9 \mathrm{mH}$ olarak hesaplanmıștır. AC gerilimin köprü diyotlarla DC gerilime çevrilmesinden sonra devrede $80 \mathrm{kHz}$ anahtarlama frekansında çalışan bir PFC şok bobini kullanılır. PFC bobini güç faktörünün aktif düzeltme devresinde gereklidir. $\mathrm{Bu}$ devrede PFC bobinin devamında PFC diyotta kullanılmaktadır. EMI filtresi ve PFC düzenleme devresinin tasarımdaki konumu Şekil 11'de gösterilmiştir.
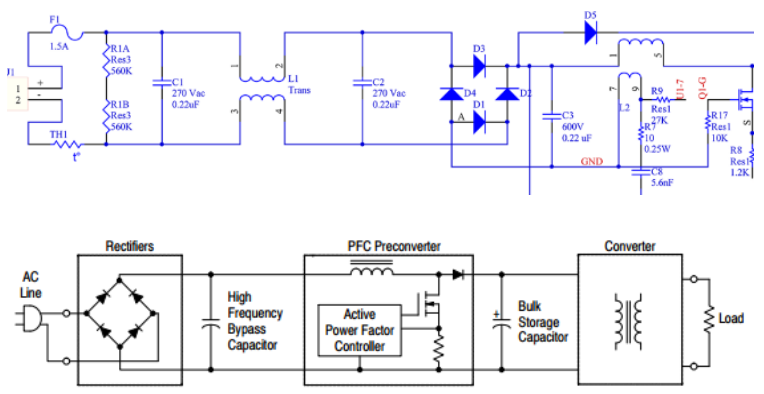

Şekil 11. EMI filtresi ve PFC düzenleme devresi (EMI filter and PFC regulation circuit)

AC-DC-DC dönüşümü yapıldıktan sonra sürücünün çıkış bölümünde sabit akım ve gerilim ile LED yükü sürülürken sıcaklık, gürülttü, harmonik gibi bozucu etkilerden kaynaklanan değişimlerle elde edilen feedback dönüşleri devrenin girişinden izolasyonlu bir şekilde karşılaştırılarak anahtarlama frekans değişimleri yapılır. Sabit akım ve sabit gerilim çıkışlarının kontrol edildiği ve sürücünün çıkış akımının değiştirilebilmesini sağlayan belirli frekanstaki PWM sinyalinin girildiği optokuplörler Şekil 12'de gösterilmiştir.

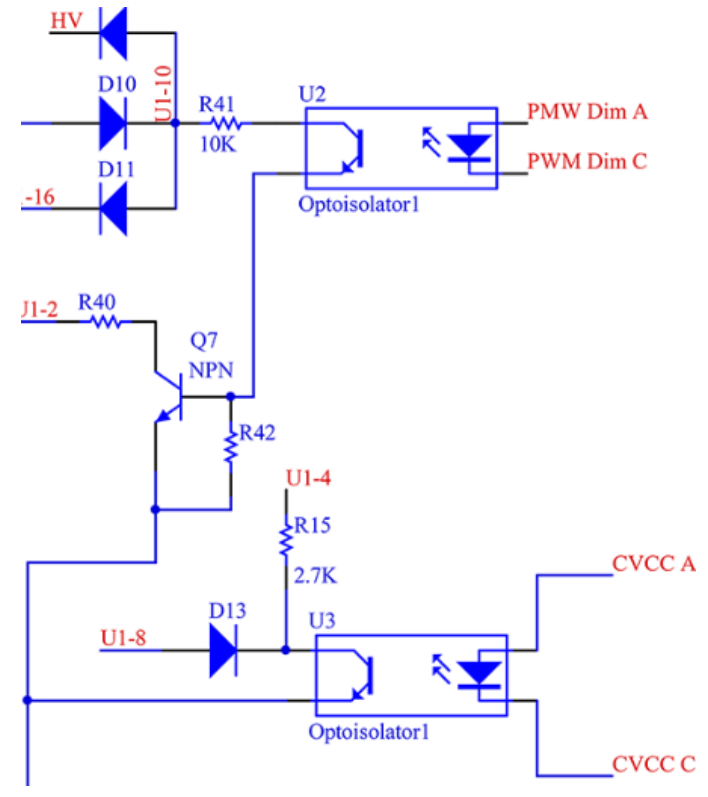

Şekil 12. Geri besleme dönüşleri ve optokuplörler (Feedback signals and optocouplers)

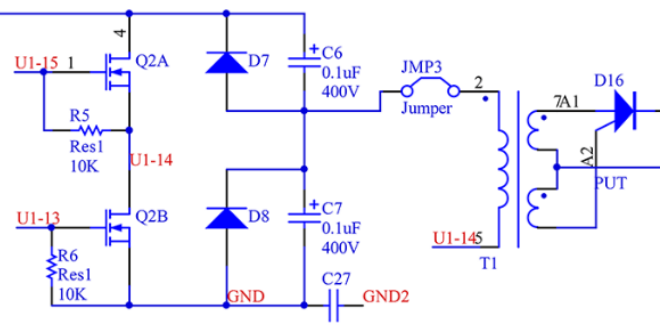

Şekil 13. Yarım köprü mimarisi ve flyback trafo konumlar1 (Half bridge topology and flyback transformer locations)

\section{GELISTTIRILEN AYDINLATMA ARMATÜRÜNÜN TERMAL ANALIZİ (THERMAL ANALYSIS OF DEVELOPED LIGHTING FIXTURE)}

Geliştirilen armatürün termal analizi için SOLIDWORKS Flow Simulation yazılimı kullanılmıștır. SOLIDWORKS Flow Simulation, SOLIDWORKS yazilımına bir eklenti olarak gelmektedir ve SOLIDWORKS ile birlikte çalışmaktadır. Flow Simulation eklentisi yardımıyla tasarımların akış, 1S1 ve 1S1 transferi analizleri gerçekleştirilebilir.

Analizin doğru bir şekilde gerçekleştirilmesi için, kullanılan LED ve LED'in sürüş akımına göre güç 
hesabı yapılmalı, her bir LED için 1 sı yükü tanımlanmalıdır.

Geliștirilen nihai tasarımda LED modül $350 \mathrm{~mA}$ sürüş akımılla beslenerek, toplamda $34 \mathrm{~W}$ sistem giriş gücü elde edilmektedir. Modül tasarımı 6 paralel, 8 seri şeklinde yapıldığından; sürüş akımı paralel kollara eşit olarak dağılarak LED başına 58,3 mA sürüş akımı elde edilecektir. LM561B kodlu LED'in veri dosyasında belirtildiği üzere, tipik sürüs akımında LED gerilimi 2,90 V-3,00 V aralığındadır.

LED gerilimi ile sürüş akımı çarpılarak LED'in üzerinde harcanan güç bulunabilir (Eşitlik 1). Termal analizde maksimum 1sı yükü altında analiz gerçekleştirilmesi gerektiğinden, hesaplama yapılırken gerilim aralığının en üst değeri alınmalıdır.

Güç $=$ Gerilim $\times$ Akım

Eşitlik 1 tasarım için uygulandığında;

$G$ üç $=3,00 \mathrm{~V} \times 0,0583 \mathrm{~A}=0,1749 \mathrm{~W}$

güç değeri elde edilir.

LED'lerin, üzerinde harcadığı enerjinin \%70-80'ini 1sıya dönüştürdüğü bilinmektedir [10]. Bu sebeple termal analiz yapılırken 1s1 yükünü $\% 80$ değerine göre hesaplamak gereklidir.

\section{$0,1749 W \times 80 / 100=0,14 W$}

Hesaplama sonucuna göre LED üzerinde harcanan 0,1749 W elektrik enerjisinin 0,14 W'1 1sıya, kalanı ise görünür 1şığa dönüştürülmektedir.

Isı transfer analizi, sıvı akışı ve 1sı aktarımını gerçekleştirebilen SOLIDWORKS Flow Simulation programı aracılığıyla gerçekleştirilecektir.

Yukarıdaki hesaplamalara göre; LED modül üzerinde her bir LED için, yani 48 LED'in her birine 0,14W 1s1 yükü tanımlanmıştır.

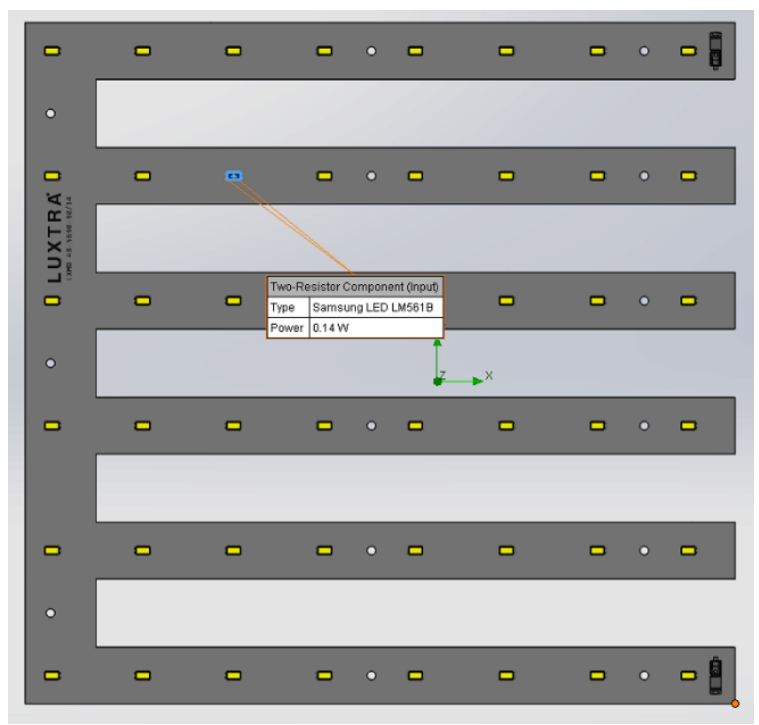

Şekil 14. LED 1S1 yükü tanımlamaları (LED heat load definitions)

Analiz için ortam sıcaklığı $+25{ }^{\circ} \mathrm{C}$ olarak ayarlanmıştır. Tüm hesaplamalar bu sıcaklık değerinde gerçekleştirilecektir.

Analiz yapılmadan önce, elektronik devre kartının termal iletkenlik katsayısının tanımlanması ve LED ile devre kartı arasındaki iletkenin (lehim) doğru bir şekilde tanımlanması son derece önemlidir.

Elektronik kart, FR-4 adı verilen cam takviyeli epoksi laminat malzemeden üretildiğinden bu malzemeye ait termal iletkenlik katsayısı 0,27 $\mathrm{W} /(\mathrm{m} \cdot \mathrm{K}) \quad$ SOLIDWORKS Flow Simulation programında ilgili ekranlara girilmiştir.

LED'ler ile elektronik devre kartı arasında kontak direnci olarak $1 \mathrm{~mm}$ kalınlığında $\mathrm{Au} / \mathrm{Sn}$ lehim alaşımı eklenmiştir.

Gerekli tanımlamalar yapıldıktan sonra, LED modül termal analiz için hazır duruma getirilmiştir. Hesaplamalar yüksek performanslı bir bilgisayar araçlığıyla yaklaşık 30 dakikada tamamlanmıştır.

Hesaplamalarda kullanılan bilgisayar $4,2 \mathrm{GHz}$ çekirdek hızına sahip INTEL Core i7-6700K modeli işlemci, 8GB GDDR5 256Bit özelliklerine sahip ekran kartı, 16GB hafizaya sahip DDR4-2400MHz hızında bellek ve $540 \mathrm{MB}-520 \mathrm{MB} / \mathrm{s}$ hızında 500GB katı hal sürücü birimi ile donatılmıştır. 


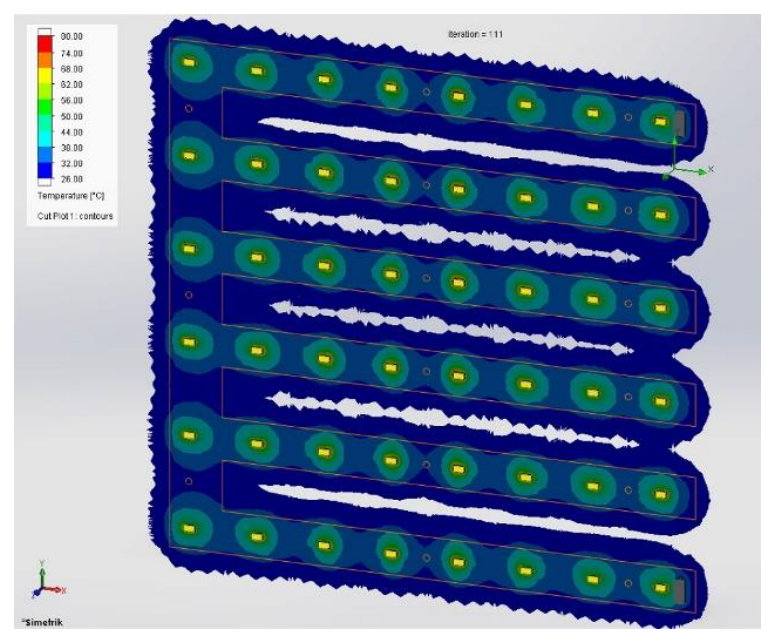

Şekil 15. Isı dağılımı gösterimi (Heat dissipation display)

Termal analiz sonucunda her bir LED için maksimum sıcaklık değeri kayıt altına alınmış ve Tablo 3 oluşturulmuştur. Tablo 3 incelendiğinde LED’lerin maksimum $90,51{ }^{\circ} \mathrm{C}$ sicaklığa çıktığı görülmüştür.
Tablo 3. Her bir LED için maksimum sıcaklık değerleri (Maximum temperature values for each LED)

\begin{tabular}{|c|c|c|}
\hline Name & Unit & Value \\
\hline VG Max Temperature (Solid) 1 & ${ }^{\circ} \mathrm{C}$ & 84,38 \\
\hline VG Max Temperature (Solid) 2 & ${ }^{\circ} \mathrm{C}$ & 86,05 \\
\hline VG Max Temperature (Solid) 3 & ${ }^{\circ} \mathrm{C}$ & 85,95 \\
\hline VG Max Temperature (Solid) 4 & ${ }^{\circ} \mathrm{C}$ & 89,75 \\
\hline VG Max Temperature (Solid) 5 & ${ }^{\circ} \mathrm{C}$ & 88,72 \\
\hline VG Max Temperature (Solid) 6 & ${ }^{\circ} \mathrm{C}$ & 87,39 \\
\hline VG Max Temperature (Solid) 7 & ${ }^{\circ} \mathrm{C}$ & 82,99 \\
\hline VG Max Temperature (Solid) 8 & ${ }^{\circ} \mathrm{C}$ & 82,67 \\
\hline VG Max Temperature (Solid) 9 & ${ }^{\circ} \mathrm{C}$ & 84,18 \\
\hline VG Max Temperature (Solid) 10 & ${ }^{\circ} \mathrm{C}$ & 86,72 \\
\hline VG Max Temperature (Solid) 11 & ${ }^{\circ} \mathrm{C}$ & 85,73 \\
\hline VG Max Temperature (Solid) 12 & ${ }^{\circ} \mathrm{C}$ & 90,04 \\
\hline VG Max Temperature (Solid) 13 & ${ }^{\circ} \mathrm{C}$ & 89,18 \\
\hline VG Max Temperature (Solid) 14 & ${ }^{\circ} \mathrm{C}$ & 88,39 \\
\hline VG Max Temperature (Solid) 15 & ${ }^{\circ} \mathrm{C}$ & 83,55 \\
\hline VG Max Temperature (Solid) 16 & ${ }^{\circ} \mathrm{C}$ & 81,87 \\
\hline VG Max Temperature (Solid) 17 & ${ }^{\circ} \mathrm{C}$ & 83,49 \\
\hline VG Max Temperature (Solid) 18 & ${ }^{\circ} \mathrm{C}$ & 86,49 \\
\hline VG Max Temperature (Solid) 19 & ${ }^{\circ} \mathrm{C}$ & 85,96 \\
\hline VG Max Temperature (Solid) 20 & ${ }^{\circ} \mathrm{C}$ & 90,51 \\
\hline VG Max Temperature (Solid) 21 & ${ }^{\circ} \mathrm{C}$ & 88,72 \\
\hline VG Max Temperature (Solid) 22 & ${ }^{\circ} \mathrm{C}$ & 88,70 \\
\hline VG Max Temperature (Solid) 23 & ${ }^{\circ} \mathrm{C}$ & 83,22 \\
\hline VG Max Temperature (Solid) 24 & ${ }^{\circ} \mathrm{C}$ & 81,49 \\
\hline VG Max Temperature (Solid) 25 & ${ }^{\circ} \mathrm{C}$ & 83,47 \\
\hline VG Max Temperature (Solid) 26 & ${ }^{\circ} \mathrm{C}$ & 86,49 \\
\hline VG Max Temperature (Solid) 27 & ${ }^{\circ} \mathrm{C}$ & 85,87 \\
\hline VG Max Temperature (Solid) 28 & ${ }^{\circ} \mathrm{C}$ & 90,47 \\
\hline VG Max Temperature (Solid) 29 & ${ }^{\circ} \mathrm{C}$ & 88,82 \\
\hline VG Max Temperature (Solid) 30 & ${ }^{\circ} \mathrm{C}$ & 88,68 \\
\hline VG Max Temperature (Solid) 31 & ${ }^{\circ} \mathrm{C}$ & 83,19 \\
\hline VG Max Temperature (Solid) 32 & ${ }^{\circ} \mathrm{C}$ & 81,47 \\
\hline VG Max Temperature (Solid) 33 & ${ }^{\circ} \mathrm{C}$ & 84,13 \\
\hline VG Max Temperature (Solid) 34 & ${ }^{\circ} \mathrm{C}$ & 86,67 \\
\hline VG Max Temperature (Solid) 35 & ${ }^{\circ} \mathrm{C}$ & 85,64 \\
\hline VG Max Temperature (Solid) 36 & ${ }^{\circ} \mathrm{C}$ & 89,87 \\
\hline VG Max Temperature (Solid) 37 & ${ }^{\circ} \mathrm{C}$ & 89,07 \\
\hline VG Max Temperature (Solid) 38 & ${ }^{\circ} \mathrm{C}$ & 88,37 \\
\hline VG Max Temperature (Solid) 39 & ${ }^{\circ} \mathrm{C}$ & 83,41 \\
\hline VG Max Temperature (Solid) 40 & ${ }^{\circ} \mathrm{C}$ & 81,49 \\
\hline VG Max Temperature (Solid) 41 & ${ }^{\circ} \mathrm{C}$ & 84,26 \\
\hline VG Max Temperature (Solid) 42 & ${ }^{\circ} \mathrm{C}$ & 85,87 \\
\hline VG Max Temperature (Solid) 43 & ${ }^{\circ} \mathrm{C}$ & 85,85 \\
\hline VG Max Temperature (Solid) 44 & ${ }^{\circ} \mathrm{C}$ & 89,63 \\
\hline VG Max Temperature (Solid) 45 & ${ }^{\circ} \mathrm{C}$ & 88,57 \\
\hline VG Max Temperature (Solid) 46 & ${ }^{\circ} \mathrm{C}$ & 87,25 \\
\hline VG Max Temperature (Solid) 47 & ${ }^{\circ} \mathrm{C}$ & 82,95 \\
\hline VG Max Temperature (Solid) 48 & ${ }^{\circ} \mathrm{C}$ & 83,08 \\
\hline
\end{tabular}

\section{DENEY (EXPERIMENT)}

Geliştirilen armatürün termal analizi yapılarak LED'lerin sıcaklığının güvenli sıcaklık aralığında kaldığı görülmüştür. Analiz sonucuna göre uzun ömürlü bir aydınlatma elemanı tasarlandığını 
söylenebilir ancak bu sonuçları gerçek ortam koşullarında deney ile doğrulamak gereklidir. Çalışmanın bu kısmında, LED panel bir saat boyunca çalıştırılacak, bu süre boyunca LED'ler üzerindeki sıcaklık değerleri kayıt altına alınacaktır. Deneyde analizden farklı olarak LED modül tek başına teste tabi tutulmayacak, LED modül kasaya monte edilecek ve armatür gövdesi üzerindeki difüzör plaka kapatılarak LED modülün sistem içerisindeki davranışı ölçümlenecektir.

LED'ler, bir elektronik devrede kullanılan ve üzerinden akım geçen tüm devre elemanları gibi 1sınırlar. Dolayısıyla, sistem performansı, lümen çıktısı ve ürün ömrü açısından sıcaklık kontrolü en kritik faktörlerden biridir. LED'lerin üreticileri tarafından öngörülen ürün eğrileri $25^{\circ} \mathrm{C}$ jonksiyon sıcaklığı koşullar için geçerlidir. Kabul edilmiş ticari armatürlerde bu değer $55-80^{\circ} \mathrm{C}$ aralığında değişiklik gösterir.

Jonksiyon Sicaklığı; LED içerisinde 1 șı̆̆ın oluştuğu noktadaki (jonksiyon) sıcaklıktır. Bu sicaklık aydınlatma üreticisi tarafından doğrudan ölçülemez çünkü üreticinin eline geçen LED hali hazırda yalıtımlı bir ünite içerisine yerleştirilmiş durumdadır. LED'in jonksiyon sıcaklığı direkt olarak ölçülemez ancak Eşitlik 2'de görüldüğü gibi hesaplanabilir (Eşitlik 2).

$\mathrm{TJ}=\mathrm{TS}+\mathrm{RthJ}-\mathrm{S} \times \mathrm{PD}$

Burada $\mathrm{T}_{\mathrm{J}}$, Junction temperature (Eklem sicaklığı), $T_{s}$, Solder point temperature (Lehim noktası sicaklığı), Rth ${ }_{\mathrm{J}-\mathrm{S}}$, Thermal resistance from junction to solder point (Eklem ile lehim noktasi arasındaki termal direnç) ve PD, Power dissipation (Güç dağılımı)'dır.

Şekil 17'de gösterildiği gibi Hioki LR-8431-20 isimli veri kaydedici ile LED Modül üzerinde 350mA sürüş akımı altında 4 noktadan 4 ayrı LED'in lehim noktası sıcaklığı ölçülmüş, bir kanaldan ise ortam sıcaklığı ölçümü yapılmıştır. Tüm bu ölçümler 5 saniyelik ölçüm aralığıyla 1 saat boyunca sürdürülmüştür.

Ölçüm için kullanılan beş kanal termokupl aşağıdaki şekilde bağlanmıştır.

CH1: L1, CH2: L48, CH3: L21, CH4: L16, CH5: ORTAM
Bir saatlik ölçüm süresi boyunca, ortam sıcaklığ 1 Şekil 15 'te görüldüğü gibi maksimum $32,6{ }^{\circ}$ C'ye ulaşmış, lehim noktası sıcaklığg ise maksimum 35,8 ${ }^{\circ} \mathrm{C}$ seviyesiyle sınırlı kalmıştır. LED üzerindeki sürüş akımının $350 \mathrm{~mA} / 6=58 \mathrm{~mA}$ gibi düşük bir seviyede olması ve PCB tasarımında bakır soğutma alanlarının düşünülmüş olması bu şekilde düşük sıcaklıkların yakalanmasında faydalı olmuştur. Tüm bu ölçümler gerçekçi sonuçlar alınması amacıyla difüzör kapalı iken yapılmıştır.

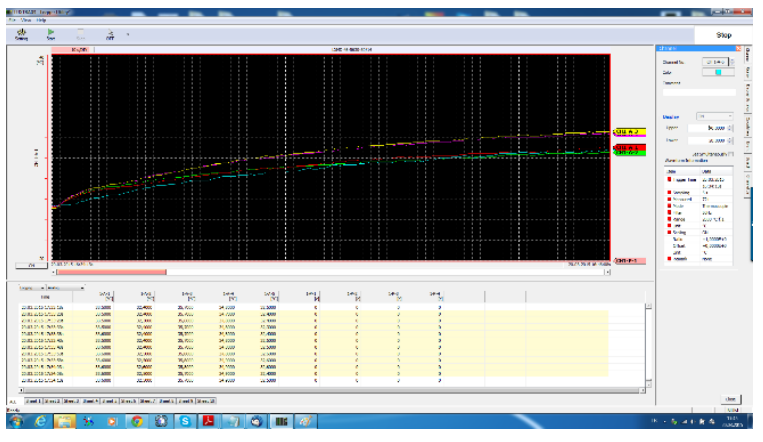

Şekil 16. Veri kaydedici bilgisayar arayüzü (Data Logger utility computer interface)

Ölçüm sonuçlarına göre; Ts lehim noktası sıcaklığı maksimum $35,8{ }^{\circ} \mathrm{C}$ seviyesine ulaşmıştır. $\mathrm{Rth}_{\mathrm{J}-\mathrm{S}} 1 \mathrm{~s} 1 \mathrm{l}$ direnci veri dosyasında belirtildiği üzere 16 ${ }^{\circ} \mathrm{C} / \mathrm{W}$ alınacaktır. PD güç hesabı da LED'in giriş gerilimi ve sürüş akımı ile Eşitlik 2'deki gibi doğrudan hesaplanacaktır (Eşitlik 2).

$\mathrm{T}_{\mathrm{J}}=35,8^{\circ} \mathrm{C}+16^{\circ} \mathrm{C} / \mathrm{W} \times 2,91 \times 0,058=38,5^{\circ} \mathrm{C}$

Hesaplamalarda gösterildiği üzere $30^{\circ} \mathrm{C}$ 'lik ortam sıcaklığında bir saatlik çalışma sonunda LED'in jonksiyon sicaklığ $1 \quad \mathrm{~T}_{\mathrm{J}} \quad 38,5 \quad{ }^{\circ} \mathrm{C} \quad$ seviyesinde tutulmuştur.

LM561B kodlu mid-power LED'in zamana bağlı 1şık akısı ölçümleri (LM-80) 100 ve $150 \mathrm{~mA}$ sürüş akımlarında 6.000 saat süre ile yapılmış, 36.000 saatten fazla ekonomik ömür garantisine sahip olduğu belirtilmiştir. LM-80 raporuna göre, $100 \mathrm{~mA}$ sürüş akımında LED'in lehim noktası sıcaklığının 55 ${ }^{\circ} \mathrm{C}, 85{ }^{\circ} \mathrm{C}$ ve $105{ }^{\circ} \mathrm{C}$ iken LED'in toplam 1 șık akısının başlangıç 1şık akısına göre \%70 seviyesine düştüğü sürenin 36.000 saatten fazla olduğu görülmektedir.

Üreticinin LM-80 raporunda belirttiği en düşük sürüş akımı $100 \mathrm{~mA}$ ve $55{ }^{\circ} \mathrm{C} \mathrm{T}_{\mathrm{s}}$ sıcaklığı dikkate aldığında geliștirilen LED modülün 36.000 saatten fazla ömre sahip olduğu sonucunu çıkartabiliriz. 


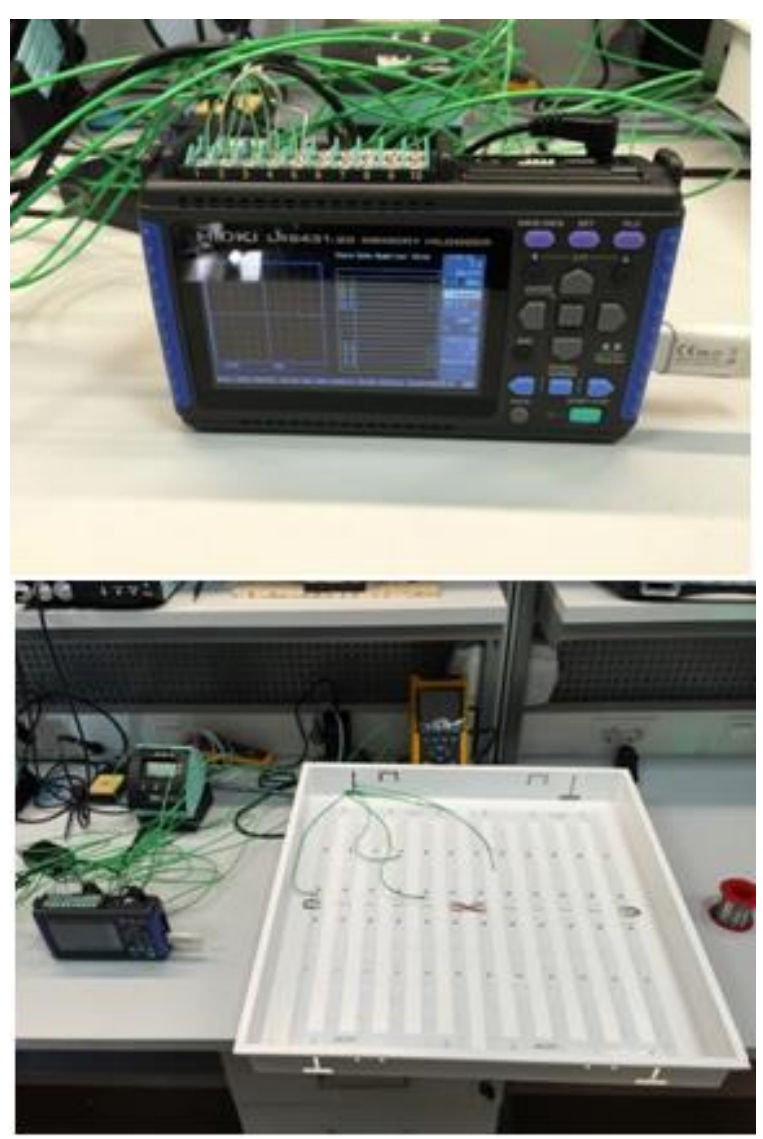

Şekil 17. Veri kaydedici ve Termokupl bağlantı noktalarının gösterimi (Display of Data Logger and Thermocouple junction)

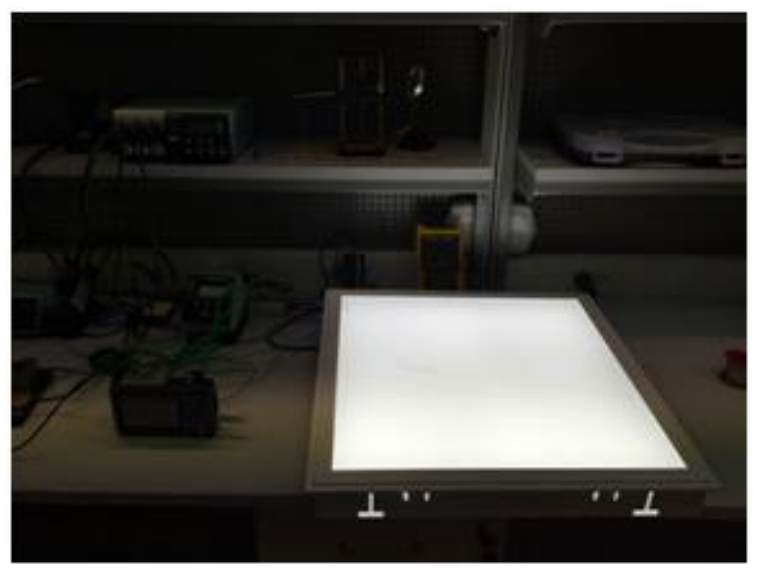

Şekil 18. Termal Ölçüm Test Düzeni (Thermal Measurement Test Layout)

\section{SONUÇLAR (CONCLUSIONS)}

Gelişen teknolojiye paralel LED teknolojisi her alanda olduğu gibi aydınlatmada da hayatımızda hızla yerini arttırmaktadır. LED aydınlatmada hala en büyük problem LED'ler üzerinde oluşan 1sıdır. LED'ler üzerindeki 1sı kontrol altına alındığında, uzun bir kullanım ömrü vaat edebilmektedir. Bu çalışmada ofis aydınlatmalarında kullanılan floresan 1şık kaynaklı geleneksel armatürlerin yerine geçecek uzun ömürlü ve yüksek verimli LED 1şık kaynaklı ofis aydınlatma armatürü geliştirilmiştir. Armatüre ait LED ışık kaynağı, armatür gövdesi, LED sürücü, optik ve 1şık açısı tasarımı yapılmıştır.

LED 1şık kaynağının 1sıl dağılımını incelemek için termal analiz çalışması yapılmıştır. Analiz çalışmasının çıktıları kayıt altına alınarak termal deneylere geçilmiştir. Termal ölçüm 1 saat boyunca sürdürülmüş, sıcaklık-zaman grafiği çıkartılmıştır.

Tasarımı yapılan LED modül, termal analiz yardımıyla değerlendirildiğinde en yüksek $90,51{ }^{\circ} \mathrm{C}$ sıcaklığa ulaşmıştır. Gerçek ortam koşullarında deney yapıldığında ise en yüksek sıcaklığın $35,8{ }^{\circ} \mathrm{C}$ olduğu görülmüştür. Her iki durumda da LED'in jonksiyon sıcaklığı üretici tarafından belirtilen 105 ${ }^{\circ} \mathrm{C}$ sınırının altında kalmaktadır.

Analiz ve deney sonucunda görüldüğü üzere, gerçekleştirilen tasarımda LED'ler üzerinde açığa çıkan 1sı, devre kartı yardımıyla LED'lerden uzaklaştırılmakta ve bu sayede LED'lerin sıcaklığ kontrol altında tutulmaktadır. LED'e ait veri dosyasından edinilen bilgiler 1şı ğında, tasarlanan LED modülün 36.000 saatten fazla ömre sahip olduğu söylenebilir. Bu da günlük 10 saat kullanımda yaklaşık 10 yıl kullanım ömrüne sahip olduğu anlamina gelmektedir.

Günümüzde LED aydınlatma alanında üretim yapan firmalar termal analiz yazılımlarının pahalı olması ve bu alanda uzmanlaşmış kişilerin az olması sebebiyle termal yönetimi büyük çoğunlukla ihmal etmektedir.

Piyasada yer alan diğer ürünlerde 36.000, 50.000 saat gibi ürün ömürleri katalog verisinde yer alsa da bu tarhminlerin büyük bir çoğunluğu teknik altyapıya dayandırılmamıștır. Belirtilen bu ömür, genellikle LED üreticisinin LED için belirttiği ömür öngörüsüdür. Ancak unutulmamalıdır ki, üretici bu ömrü yalnızca belirtilen koşullarda garanti eder. Bu koşulların oluşup oluşmadığı ise termal analiz ve deney yardımıyla doğrulanabilir.

$\mathrm{Bu}$ çalışma ile termal yönetimin önemi vurgulanmış, sıcaklığın LED'ler üzerindeki etkisi tartışılmıştır. Bu çalışma, LED'li 1şık kaynaklarının 
ömrünü tahmin edebilmek için termal analiz yapılması gerektiğini göstermektedir.

Geliştirilen LED 1şık kaynaklı ofis aydınlatma armatürü, iç mekân aydınlatmalarında floresan 1 şı kaynaklı armatürlerin yerine geçecek yüksek 1 ş1k verimli, uzun ömürlü iyi bir alternatiftir.

\section{KAYNAKLAR (REFERENCES)}

[1] M. Ali, M. Orabi, M.E. Ahmed, A.E. Aroudi, Design considerations of a singlestage LED lamp driver with power factor correction, Proc. Int. Conf. Electr. Power Energy Convers. Syst. (2011), s. 1-6.

[2] B. Lee, C. Kim, K. Park, G. Moon, A new singlestage PFC AC/DC converter with low link-capacitor voltage, J. Power Electron. 7 (2007), 328.

[3] S. Ahmad, N.M.L. Tan, A non-electrolyticcapacitor low-power AC-DC singlestage SEPICFlyback LED converter, J. Telecommun. Electron. Comput. Eng. 8 (2016), pp. 105-111.

[4] R. Petrella, A. Revelant, P. Stocco, A novel proposal to increase the power factor of photovoltaic grid-connected converters at light loads, Proc. Int. Univ. Power Eng. Conf. (2009), pp. 1-5.

[5] AN Padmasali, SG Kini (2015). Prognostic algorithms for L70 life prediction of solid state lighting, Lighting Res. Technol. 2016; Vol. 48: pp. 608-623.

[6] Ashok Sivaji, Sajidah Shopian, Zulkifle Mohd Nor, Ngip-Khean Chuan, Shamsul Bahri (2013). Lighting does matter: Preliminary assessment on office workers, 1.

[7] Byung-Lip Ahn, Cheol-Yong Jang, Seung-Bok Leigh, Seunghwan Yoo, Hakgeun Jeong (2013). Effect of LED lighting on the cooling and heating loads in office buildings. Applied Energy, pp. 14841489.

[8] IESNA 2000, IESNA Lighting Design Guide in The IESNA lighting handbook. Reference \& application. 9th edition. New York: Mark S. Rea.

[9] Paola Iacomussi, Michela Radis, Giuseppe Rossi, Laura Rossi (2015). Visual Comfort with LED Lighting. Energy Procedia 78, 734.
[10] De-Shau Huang, Tzu-Ching Chen, Liang-Te Tsai, Ming-Tzer Lin (2018). Design of fins with a grooved heat pipe for dissipation of heat from highpowered automotive LED headlights. Energy Conversion and Management, pp. 550-558

[11] Jin-Cherng Shyu, Keng-Wei Hsu, Kai-Shing Yang, Chi-Chuan Wang (2011). Thermal characterization of shrouded plate fin array on an LED backlight panel. Applied Thermal Engineering, pp. 2909-2915.

[12] Emre Erkin, M. Berker Yurtseven, Önder Güler, Sermin Onaygil (2014). LED panel armatürlerin ofis aydınlatmasında retrofit amaçlı kullanımının incelenmesi, s. 1-7.

[13] LM561B-5630 Middle Power LED Datasheet, https://media.digikey.com/pdf/Data\%20Sheets/Sams ung\%20PDFs/LM561B_5630MidPwrLED_Rev001. pdf (Erişim tarihi: 25.03.2019).

[14]J.T. Hwang, M.S. Jung, D.H. Kim, J.H. Lee, M. H. Jung, J.H. Shin. Off-the-line primary side regulation LED lamp driver with single-stage PFC and TRIAC dimming using LED forward voltage and duty variation tracking control. IEEE J. Solid-State Circuits, 47 (2012), pp. 3081-3094.

[15] B. Axelrod, Y. Berkovich, S. Tapuchi, A. Ioinovici. Single-stage single-switch switchedcapacitor buck/buck-boost-type converter. IEEE Trans. Aerosp. Electron. Syst., 45 (2009), pp. 419430.

[16] A new High-power LED drive power design based on "PFC+LLC+VC, CC" topology structure. Wenfang Li, Haixia Li, Jiayi Chen. International Conference on Cyberspace Technology (CCT 2013), pp. 20-23.

[17] W.R. Ryckaert, K.A.G. Smet, I.A.A. Roelandts, M. Van Gils, P. Hanselaer (2012). Linear LED tubes versus fluorescent lamps: An evaluation. Energy and Buildings 49, pp. 429-436. 


\section{Emre YILMAZ}

Emre Yllmaz graduated from Atılım University Electrical and Electronics Engineering Department in 2013. He completed his master's degree in Gazi University Industrial Design Engineering Department and started his doctorate education in the same department in 2019. He has been working in Lighting Equipment Sales as a business partner since 2017.

\section{İsmail ŞAHIN}

Assoc. Prof. İsmail Şahin, born in 1971, received his BS and MS degrees and his PhD from Gazi University, Ankara, Turkey. He became Assistant Professor at Gazi University in 2009. He has been Associate Professor in Industrial Design Engineering, Gazi University since 2015. His research areas include mechanical design, product design, computer aided design, composites materials and artificial intelligence (artificial neural network, expert systems etc.) and metaheuristic optimisation methods. 